Supplementary File

\title{
An Integrative Proteomic Approach Identifies Novel \\ Cellular SMYD2 Substrates
}

Hazem Ahmed ${ }^{1}$, Shili Duan², Cheryl Arrowsmith ${ }^{1,2}$, Dalia Barsyte-Lovejoy', Matthieu Schapira ${ }^{1,3, *}$

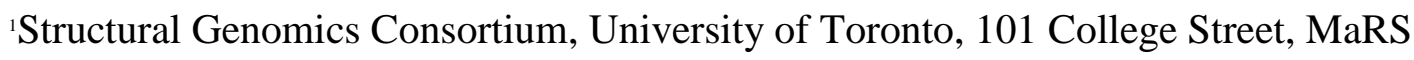

Centre, South Tower, Toronto, ON M5G 1L7, Canada.

${ }^{2}$ Princess Margaret Cancer Centre and Department of Medical Biophysics, University of Toronto, Toronto, ON M5S 1A8, Canada.

${ }^{3}$ Department of Pharmacology and Toxicology, University of Toronto; 1 King's College Circle, Toronto, ON M5S 1A8, Canada.

Running Title: Novel Cellular SMYD2 Substrates

Keywords: SMYD2, non-histone substrates, lysine methylation, data integration, panmethyl lysine antibody.

* Correspondence to: matthieu.schapira@utoronto.ca 
Figure S-1: Mapping all 127 hits onto protein interaction networks. STRING database $^{1}$ was used to generate protein functional association and physical interaction networks for all 127 proteins passing our two hard filters.

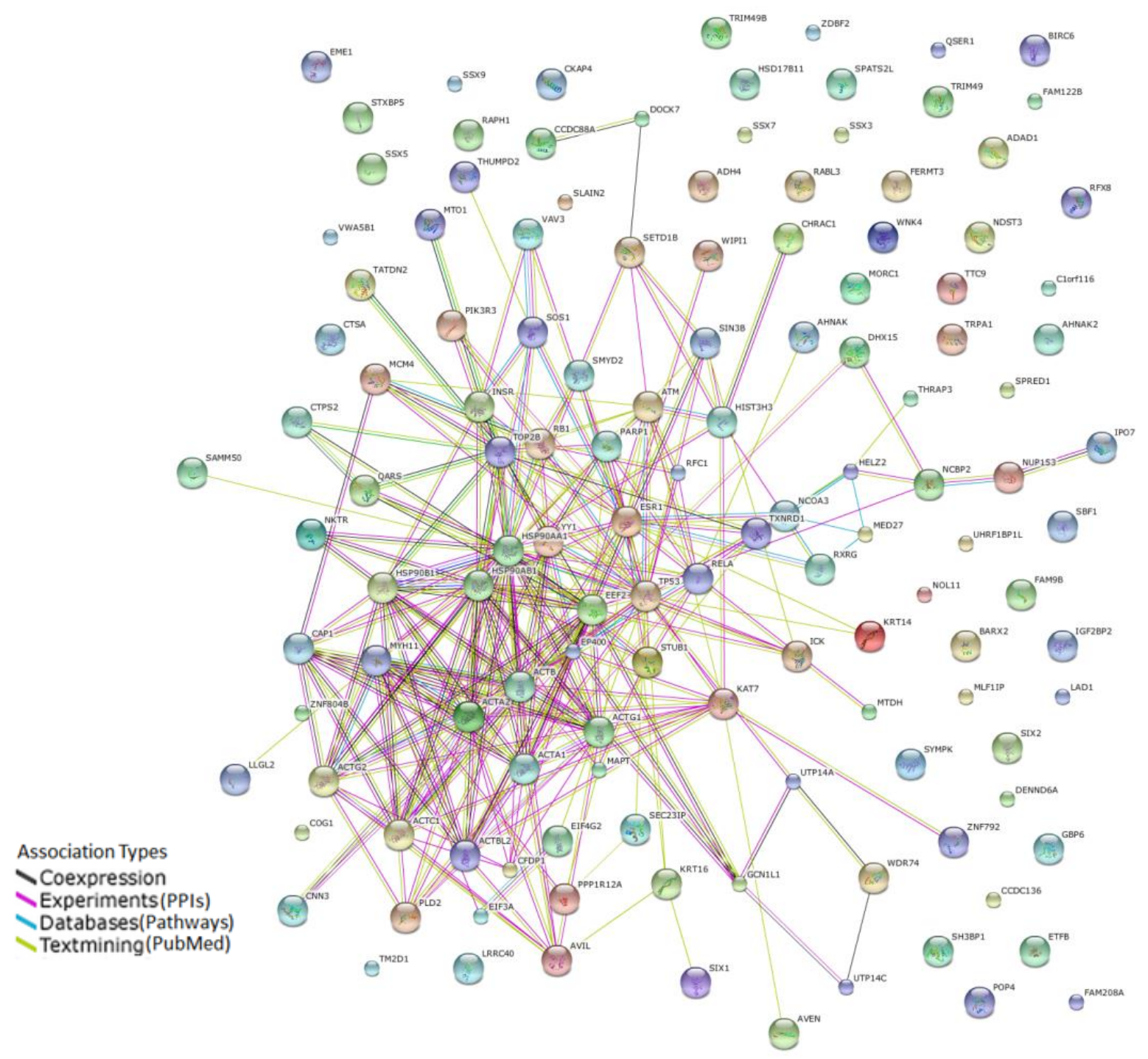


Figure S-2: Identified novel SMYD2 substrates can be nuclear or cytoplasmic. Cellular localization of confirmed SMYD2 substrate GFP fusions (green). DAPI images (blue) below indicate nuclei. The scale bar represents $15 \mu \mathrm{m}$.
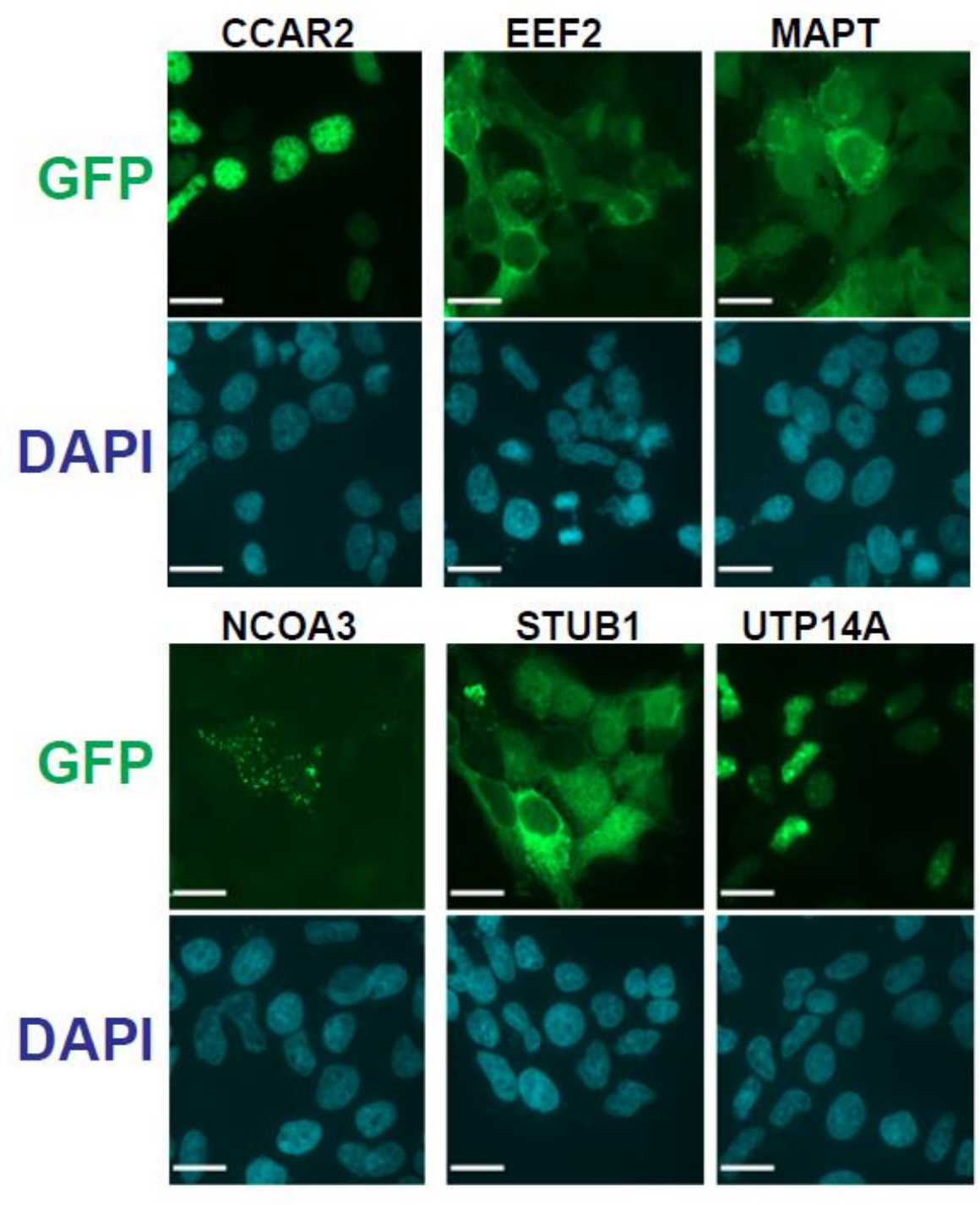
Figure S-3: A more permissive SMYD2 selectivity profile produces novel substrate candidates. A. Enriched SMYD2 specificity profile used in this work. B. Substrate candidates with major mismatches (bold) from the enriched SMYD2 specificity profile but that directly interact experimentally with SMYD2 ${ }^{2}$ are shown.

\begin{tabular}{|c|c|c|c|c|c|c|}
\hline A & \multicolumn{6}{|c|}{$[\mathrm{LFM}]_{-1}-\left[\mathrm{K}_{\mathrm{me1}}\right]-[\mathrm{AFYMSHRKG}]_{+1}-[\text { LYKQSPG }]_{+2}$} \\
\hline \multirow{6}{*}{ B } & TP53 & K370 & $\mathrm{L}$ & K & $S$ & $\mathrm{~K}$ \\
\hline & BTF3 & $\mathrm{K} 2$ & M & K & $\mathbf{E}$ & $\mathbf{T}$ \\
\hline & NACA & K76 & $\mathbf{R}$ & $\mathrm{K}$ & $A$ & $M$ \\
\hline & CBWD2 & K204 & K & K & $A$ & I \\
\hline & CKAP5 & K1093 & $S$ & K & $\mathbf{P}$ & $M$ \\
\hline & & & -1 & $*$ & 1 & 2 \\
\hline
\end{tabular}


Table S-1: Summary of filters implemented and associated data source. Hard filters must be met. Soft filters are selection criteria used as weighting factors.

\begin{tabular}{|c|c|c|}
\hline $\begin{array}{l}\text { Questions (in a descending order of importance to } \\
\text { the selection process) }\end{array}$ & Data Source & $\begin{array}{l}\text { Filter } \\
\text { Type }\end{array}$ \\
\hline $\begin{array}{l}\text { Is the lysine under investigation reported to be } \\
\text { methyalted, in the first place? }\end{array}$ & $\begin{array}{l}\text { Phosphosite Plus DB, Mass } \\
\text { Spec experiments }\end{array}$ & Hard \\
\hline $\begin{array}{l}\text { Is the flanking sequence around this lysine similar } \\
\text { to SMYD2 substrate preference? }\end{array}$ & $\begin{array}{l}\text { Published Specificity + } \\
\text { Published Substrates }\end{array}$ & Hard \\
\hline $\begin{array}{l}\text { Does the KMT target having this lysine directly } \\
\text { interact with SMYD2 }\end{array}$ & $\begin{array}{l}\text { Published interaction data + } \\
\text { Curated PPI Databases }\end{array}$ & Soft \\
\hline $\begin{array}{l}\text { Does it share interaction partners with SMYD2, } \\
\text { e.g., HSP90, or other SMYD2 published substrates? }\end{array}$ & $\begin{array}{l}\text { STRING Interaction network } \\
+ \text { clustering analysis }\end{array}$ & Soft \\
\hline Is the KMT target localized in the cytoplasm? & UniProt, GeneCards DB & Soft \\
\hline $\begin{array}{l}\text { Is the KMT target notably expressed in the heart } \\
\text { and/or brain? }\end{array}$ & $\begin{array}{l}\text { PubMed, Human Proteome } \\
\text { Map + Human Protein Atlas }\end{array}$ & Soft \\
\hline $\begin{array}{l}\text { Is the KMT target functionally related to SMYD2? } \\
\text { Similar cellular process, biological pathway? }\end{array}$ & $\begin{array}{l}\text { Gene Ontology + Reactome, } \\
\text { KEGG and STRING-DB }\end{array}$ & Soft \\
\hline $\begin{array}{l}\text { Is there a reliable literature support associating the } \\
\text { KMT target with SMYD2? }\end{array}$ & Text Mining, STRING-DB & Soft \\
\hline
\end{tabular}


Table S-2: 160 sites selected from the methylome matching our permissive SMYD2 signature motif. A single methylation site may be present more that once. For example, TP53-K370 is present three times because it is reported to be mono- di- and trimethylated in the methylome.

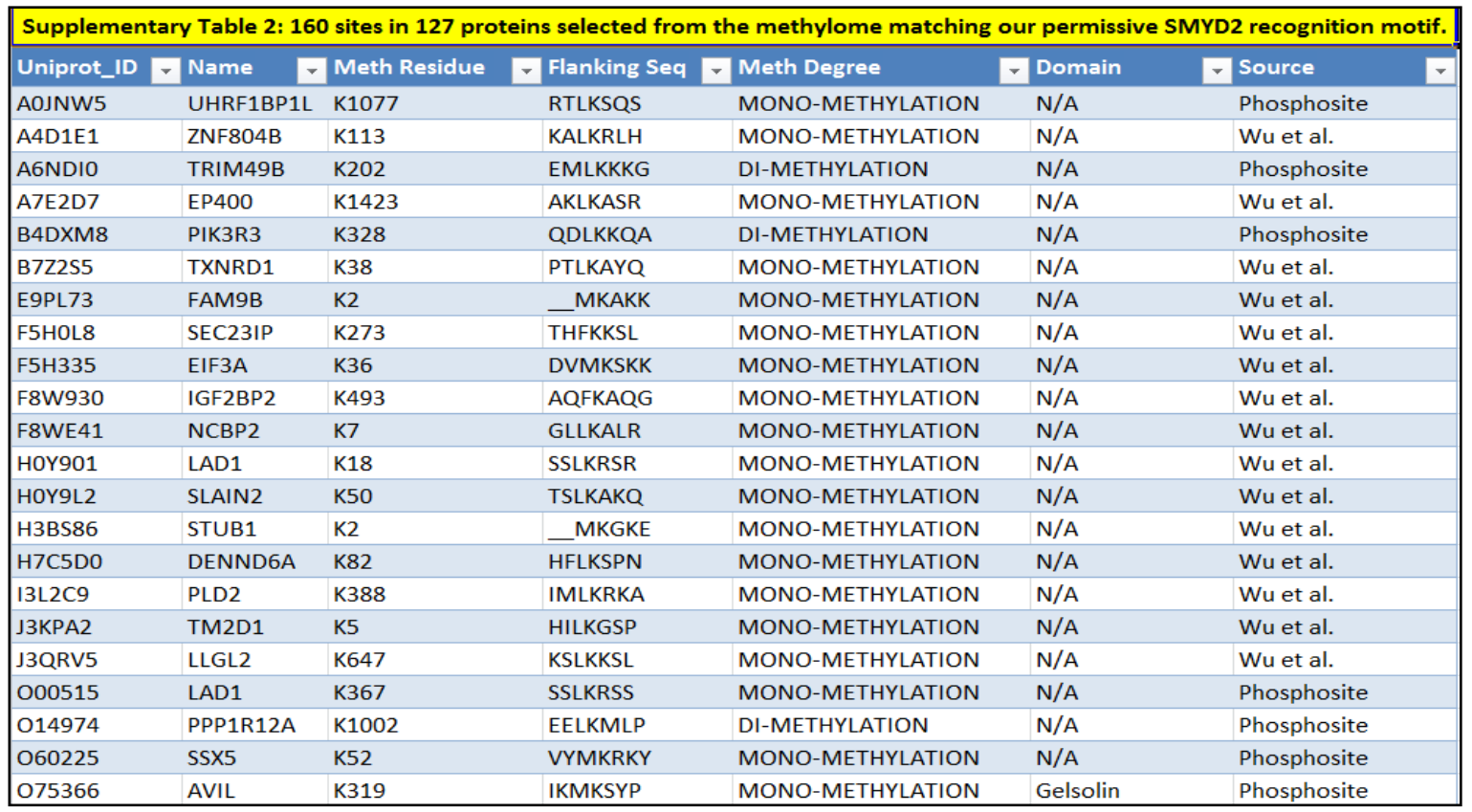

\section{See excel file for full list}

\section{References}

(1) Franceschini, A.; Szklarczyk, D.; Frankild, S.; Kuhn, M.; Simonovic, M.; Roth, A.; Lin, J.; Minguez, P.; Bork, P.; von Mering, C., STRING v9. 1: protein-protein interaction networks, with increased coverage and integration. Nucleic Acids Res. 2013, 41, (D1), D808-D815.

(2) Marcon, E.; Ni, Z.; Pu, S.; Turinsky, A. L.; Trimble, S. S.; Olsen, J. B.; Silverman-Gavrila, R.; Silverman-Gavrila, L.; Phanse, S.; Guo, H., Human-chromatin-related protein interactions identify a demethylase complex required for chromosome segregation. Cell Rep. 2014, 8, (1), 297-310. 